\title{
Hydrogel-based delivery of Tat-fused protein Hsp70 protects dopaminergic cells in vitro and in a mouse model of Parkinson's disease
}

\author{
Marta Tunesi id ', llaria Raimondi ${ }^{2}$, Teresa Russo ${ }^{3}$, Laura Colombo ${ }^{4}$, Edoardo Micotti ${ }^{2}$, Edoardo Brandi ${ }^{2}$, \\ Pamela Cappelletti ${ }^{5}$, Alberto Cigada ${ }^{1}$, Alessandro Negro ${ }^{6}$, Luigi Ambrosio ${ }^{3,7}$, Gianluigi Forloni ${ }^{2}$, Loredano Pollegioni ${ }^{5}$, \\ Antonio Gloria ${ }^{3}$, Carmen Giordano ${ }^{1}$ and Diego Albani ${ }^{2}$
}

\begin{abstract}
Neurodegenerative disorders such as Parkinson's disease (PD) have no effective therapies. However, many promising drugs are precluded from clinical trials because of their poor brain availability. The chaperone protein Hsp70 has been reported to be effective in PD models, but its brain targeting is challenging. We developed a novel brain Hsp70 delivery system using injectable, biocompatible, and biodegradable semi-interpenetrating polymer networks of collagen (COLL) and low-molecular-weight hyaluronic acid (LMW HA) structured with gelatin particles. We produced human recombinant Hsp70-1A fused with the cell-penetrating peptide Tat (Tat-Hsp70) that was neuroprotective in vitro against the dopaminergic toxin 6-hydroxydopamine (6-OHDA). We assessed Tat-Hsp70 release from the selected COLL-LMW HA composites in vitro, observing a 95\% release of loaded protein after $96 \mathrm{~h}$. The release kinetics FITTED the Korsmeyer-Peppas model (regression coefficient 0.98) and the released Tat-Hsp70 remained neuroprotective for SH-SY5Y cells. Magnetic resonance imaging revealed that COLL-LMW HA composites lasted at least $96 \mathrm{~h}$ at the brain level, and in vivo Tat-Hsp70 release studies indicated that hydrogel presence is pivotal for a spatially focused neuroprotective effect. In an in vivo model of dopaminergic degeneration, Tat-Hsp70-loaded composites conveyed neuroprotection at both the behavioral and dopaminergic neuronal levels against the striatal injection of 6-OHDA. After the injection of Tat-Hsp70-loaded composites, mice showed a transient inflammatory response, with a decrease in GFAP and CD11b immunostaining after 7 days. Our delivery system enabled the effective brain release of Tat-Hsp70 and is ready for further improvements.
\end{abstract}

\section{Introduction}

Parkinson's disease (PD) is a neurodegenerative disorder affecting $1-2 \%$ of the population over 60 years of age and $4-5 \%$ over 85 years of age ${ }^{1}$. This disease causes

\footnotetext{
Correspondence: Carmen Giordano (carmen.giordano@polimi.it) 'Department of Chemistry, Materials and Chemical Engineering "G. Natta", Politecnico di Milano, Milan, Italy

${ }^{2}$ Department of Neuroscience, Istituto di Ricerche Farmacologiche Mario Negri IRCCS, Milan, Italy

Full list of author information is available at the end of the article.
}

reduced dopamine production due to progressive degeneration of dopaminergic neurons in the substantia nigra pars compacta and accumulation of cytoplasmic inclusions (Lewy bodies) mainly composed of misfolded $\alpha$ synuclein $(\alpha$-syn), a protein prone to self-aggregation and toxicity ${ }^{2,3}$. Current therapies are symptomatic rather than restorative and aim to raise dopamine levels in the brain ${ }^{4}$.

Heat shock proteins regulate the folding, refolding, trafficking, and degradation of proteins, and form a fundamental defense mechanism against stress-induced

\section{(c) The Author(s) 2019}

(c) (i) Open Access This article is licensed under a Creative Commons Attribution 4.0 International License, which permits use, sharing, adaptation, distribution and reproduction c. in any medium or format, as long as you give appropriate credit to the original author(s) and the source, provide a link to the Creative Commons license, and indicate if changes were made. The images or other third party material in this article are included in the article's Creative Commons license, unless indicated otherwise in a credit line to the material. If material is not included in the article's Creative Commons license and your intended use is not permitted by statutory regulation or exceeds the permitted use, you will need to obtain permission directly from the copyright holder. To view a copy of this license, visit http://creativecommons.org/licenses/by/4.0/. 
protein misfolding and aggregation. Heat shock protein 70 (Hsp70) colocalizes with Lewy bodies and reduces $\alpha$ syn toxicity ${ }^{2,5,6}$ by acting on $\alpha$-syn oligomers and aiding clearance $^{7}$. Thus, targeting Hsp70 represents a potentially innovative therapeutic strategy against PD. Hsp70 has also emerged as a promising tool against myocardial infarction and cerebral ischemia, whereas inhibitors of its activity are required for cancer treatments, because Hsp70 interferes with pro-apoptotic factors ${ }^{8}$.

The low cell membrane permeability and short half-life of Hsp70 prevents its efficient delivery and, furthermore, repeated doses are required to maintain a therapeutic level. Enhancing Hsp70 expression by Hsp90 inhibitors such as geldanamycin or its derivatives is limited by hepatic or gastrointestinal toxicity, restricted passage across the blood-brain barrier, poor oral bioavailability, and an inability to control doses ${ }^{9}$. Yurinskaya et al. ${ }^{10}$ used polyelectrolyte microcapsules to deliver Hsp70 to neutrophils, while protecting from enzymatic degradation and oxidation. To achieve prolonged release in rats with acute ischemic stroke, Shevtsov et al. ${ }^{11}$ implanted alginate granules subcutaneously in the mid-scapular region. Abkin et al. ${ }^{12}$ considered a carbopol-based gel for Hsp70 release for the treatment of melanoma. However, no hydrogel-based systems have been described for direct injection and in situ delivery for central nervous system (CNS) applications.

Lee et al. ${ }^{13}$ proposed a similar approach for the treatment of myocardial infarction by focusing on heat shock protein 27 (Hsp27). For faster and more efficient translocation across biological membranes, Lee et al. ${ }^{13}$ fused recombinant Hsp27 to a transcriptional activator (Tat, a cell-penetrating peptide) and loaded Tat-Hsp27 into poly (lactic-co-glycolic acid) microspheres for embedment in injectable alginate hydrogels.

Similar to the case of Hsp27, Tat-Hsp70 proved more effective than Hsp70 in crossing biological membranes and counteracted PD-oxidative stress in vitro and in systemic application in vivo ${ }^{14}$.

Based on these results, in this study, we prepared and characterized biocompatible, biodegradable, injectable systems for the localized delivery of Tat-Hsp70 in the striatum and demonstrated the effectiveness of the selected prototype in counteracting PD-related degeneration. For the candidate systems, we examined the viscoelastic properties, flow behavior, functional injectability, and in vitro/in vivo biological performances. For the selected prototype, we assessed the in vitro/in vivo release profile of Tat-Hsp70 and neuroprotection, motor coordination, and balance abilities in mouse models of PD.

The proposed delivery system consists of a semiinterpenetrating polymer network (semi-IPN) prepared by promoting collagen (COLL) fibrillogenesis in the presence of hyaluronic acid (HA) and loaded with gelatin particles. We selected a semi-IPN, because it offers the advantage of joining two independent and physically interlocked networks, thus combining the features of both polymers in a tunable manner. Semi-IPNs consist of one or more polymer networks where linear or branched polymers are dissolved. These materials are characterized by penetration on a molecular scale of (at least) one of the networks by (at least) a subset of the linear or branched macromolecules. Semi-IPNs differ from IPNs, because the constituent macromolecules can be separated from the constituent polymer network(s) without breaking of chemical bonds.

Hydrogels composed of extracellular matrix components are widely exploited because of their tissue compatibility and viscoelastic properties. Type I COLL is an appealing candidate for CNS applications because of its ability to self-assemble and form a fibrillar structure in physiological conditions without a crosslinking agent, thus reducing the risk of inflammation and cytotoxicity at the injection site. We selected a final COLL concentration of $1.2 \mathrm{mg} / \mathrm{mL}$, because under physiological conditions $\left(35-37^{\circ} \mathrm{C}, \mathrm{pH} 7.2\right)$, COLL fibrils are formed more rapidly at this concentration and the enthalpy of their assembly is minimal ${ }^{15}$. HA is a major extracellular matrix component in the brain, is involved in the development and homeostasis of the CNS, and its biological functions depend on the molecular weight ${ }^{16,17}$. The use of HA is advantageous for in vivo injections. Due to its remarkable hydration capacity, HA forms extensive hydrogen bonds with water. This property allows HA to undergo deformation and act as a shearthinning agent in cogels. Unmodified HA shows poor mechanical properties, but chemical modifications might hinder its biocompatibility. Xin et al. ${ }^{18}$ demonstrated that interpenetration with a fibrillary COLL scaffold stabilizes its mechanical properties due to specific interactions between COLL and HA during network formation.

Biodegradability avoids additional surgery for removal of the device after depletion of the Tat-Hsp70 load and injectability is fundamental to limiting the invasiveness of brain implantation. Injection through a needle negatively affects the rheological behavior and viscoelastic properties of hydrogels ${ }^{19}$. To improve these viscoelastic properties before in vivo injection but without altering the gel-like behavior, we reinforced the COLL/HA gels with gelatin particles. Gelatin has been widely applied ${ }^{20}$. In this work, we selected gelatin for its good cytocompatibility and low immunogenicity, combined with ease of production and low costs. Furthermore, the inclusion of gelatin has no heavy impact on our basic hydrogel formulation.

\section{Experimental procedures}

In the following paragraphs, we describe only the main experimental procedures. In Supplementary Material S1, we detail the reagent list and procedures related to the 
expression, purification, and biochemical characterization of Hsp70-1A and Tat-Hsp70-1A; the characterization of hydrogels, particles, composites, and Tat-Hsp70-loaded composites; the evaluation of peripheral inflammatory response with the air pouch model; and the behavioral experiments.

\section{Biological characterization of Hsp70 and Tat-Hsp70}

We assessed the neuroprotective effect of both purified Hsp70s on SH-SY5Y cells. We induced excess production of reactive oxygen species by 6-hydroxydopamine (6OHDA). We dissolved 6-OHDA in buffer (e.g., saline or phosphate-buffered saline (PBS), as suggested by the manufacturer) or $\mathrm{H}_{2} \mathrm{O}_{2}$. The day after plating, we incubated the cells $\left(62.5-93.75 \times 10^{3} / \mathrm{cm}^{2}\right)$ with $250 \mathrm{nM}$ Hsp70 or Tat-Hsp70. After $2 \mathrm{~h}$, we added 6-OHDA $(50 \mu \mathrm{M})$ or $\mathrm{H}_{2} \mathrm{O}_{2}(50,75 \mu \mathrm{M})$, and $24 \mathrm{~h}$ later we evaluated the cell metabolic activity via resazurin assay by measuring the fluorescence at $590 \mathrm{~nm}$ (excitation wavelength of $560 \mathrm{~nm}$ ). We normalized the results to controls in standard medium.

We confirmed the neuroprotective effect of Tat-Hsp70 with mesencephalic dopaminergic neurons from CD-1 mice (Charles River Laboratories, Calco, Italy) on embryonic day 13 . We plated neurons $\left(1.5 \times 10^{5} / \mathrm{cm}^{2}\right)$ on poly-D-lysine-coated plates. On day 5 , we incubated the cells with $250 \mathrm{nM}$ Tat-Hsp70 for $3 \mathrm{~h}$ and added $3 \mu \mathrm{M}$ Tat$\alpha$-syn. After $24 \mathrm{~h}$, we detected dopaminergic neurons by immunocytochemistry using an anti-tyrosine hydroxylase (TH) antibody (1:400; Chemicon, EMD Millipore, Billerica, MA, USA). We recorded the number of TH-positive neurons and the average neurite length using ImageJ software (http://rsbweb.nih.gov/ij/). We normalized the results to controls in standard medium.

\section{Preparation of hydrogels, particles, and hydrogel-based composites}

We prepared COLL low-molecular-weight HA (COLLLMW HA) and COLL high-molecular-weight HA (COLLHMW HA) semi-IPNs by promoting COLL fibrillogenesis in the presence of LMW or HMW HA, respectively. We mixed 8 parts $(\mathrm{v} / \mathrm{v})$ ultrapure type I COLL from bovine skin $(3 \mathrm{mg} / \mathrm{mL})$ with 1 part $(\mathrm{v} / \mathrm{v}) 10 \times$ PBS and 1 part $(\mathrm{v} / \mathrm{v})$ $0.1 \mathrm{~N} \mathrm{NaOH}$. We dissolved LMW HA $\left(\mathrm{M}_{\mathrm{w}}=1 \times 10^{5} \mathrm{Da}\right.$, Altergon, Morra de Sanctis, Italy) or HMW HA $\left(\mathrm{M}_{\mathrm{w}}=\right.$ $1.6 \times 10^{6} \mathrm{Da}$, Altergon) in MilliQ water and autoclaved the solutions $\left(121.5^{\circ} \mathrm{C}\right.$ for $15 \mathrm{~min}$ or, alternatively, with an equivalent time $\mathrm{F}_{0}$ equal to 13). We mixed COLL and HA solutions to final concentrations of $1.2 \mathrm{mg} / \mathrm{mL}$ and $2.5 \mathrm{mg} /$ $\mathrm{mL}$, respectively. We incubated the solution at $37^{\circ} \mathrm{C}$ for $1 \mathrm{~h}$ to promote COLL fibrillogenesis. As a comparison for rheological, morphological, and peripheral inflammatory studies, we prepared COLL gels with a COLL concentration of $1.2 \mathrm{mg} / \mathrm{mL}$.
We prepared type A gelatin ( $175 \mathrm{~g}$ Bloom) particles by optimizing a double desolvation-based protocol $^{21}$ in terms of temperature $\left(40^{\circ} \mathrm{C}\right)$ and $\mathrm{pH}(3.0)$.

We suspended the particles $(5.1 \mathrm{mg} / \mathrm{mL})$ in MilliQ water, sonicated the suspension for $1 \mathrm{~h}$, added $(1: 10 \mathrm{v} / \mathrm{v})$ to the COLL-HA solutions to a final concentration of 10,25 , or $50 \mu \mathrm{g} / \mathrm{mL}$, and incubated the solutions for $1 \mathrm{~h}$ at $37^{\circ} \mathrm{C}$.

\section{Preparation of Tat-Hsp70-loaded composites}

We loaded the selected COLL-LMW HA composites (COLL-LMW HA semi-IPNs loaded with particles to a final concentration of $25 \mu \mathrm{g} / \mathrm{mL}$ ) with Tat-Hsp70 $(0.35 \mu \mathrm{g} / \mathrm{mL})$ and incubated the solutions for $1 \mathrm{~h}$ at $37^{\circ} \mathrm{C}$.

\section{Tat-Hsp70 release (in vitro)}

To quantify Tat-Hsp70 release from Tat-Hsp70-loaded composites in vitro, we prepared the samples $(0.5 \mathrm{~mL})$ in 48-well plates, flooded them with $0.75 \mathrm{~mL}$ PBS, and placed them on an orbital shaker at $25^{\circ} \mathrm{C}$. We replaced the supernatants with fresh PBS after 1, 4, 24, 72, 96, and $168 \mathrm{~h}$, and estimated the Tat-Hsp70 amount via silver staining after electrophoretic separation on $8 \%$ polyacrylamide gels.

To assess whether released Tat-Hsp70 retains its neuroprotective effect, we flooded Tat-Hsp70-loaded composites $(0.5 \mathrm{~mL})$ with $0.75 \mathrm{~mL}$ medium and replaced the supernatants with fresh medium after 1, 4, 24, 72, and $96 \mathrm{~h}$. The day after plating, we incubated SH-SY5Y cells $\left(62.5 \times 10^{3} / \mathrm{cm}^{2}\right)$ with supernatants (a subset diluted with medium in three conditions: DIL1, not diluted; DIL2, 1:4 $\mathrm{v} / \mathrm{v}$; and DIL3, $1: 10 \mathrm{v} / \mathrm{v}$ ). After $2 \mathrm{~h}$, we added $50 \mu \mathrm{M} 6-$ OHDA or $\mathrm{H}_{2} \mathrm{O}_{2}$, and $24 \mathrm{~h}$ later we measured the cell metabolic activity by resazurin assay. We normalized the results to controls in standard medium.

To exclude the involvement in neuroprotection of polymer components due to hydrogel degradation, we repeated the investigation for unloaded COLL-LMW HA composites.

\section{In vivo investigations}

We housed $\mathrm{CD}-1$ and $\mathrm{C} 57 \mathrm{Bl} / 6 \mathrm{~N}$ mice with a regular $12: 12 \mathrm{~h} \mathrm{light/dark}$ cycle at a room temperature of $21 \pm$ $1{ }^{\circ} \mathrm{C}$ and relative humidity of $\sim 60 \%$. The mice had free access to water and standard rodent chow. We ran experiments according to Italian Governing Law (D.lgs 26/2014; Authorization number 19/2008-A, issued 6 March 2008 by Ministry of Health), the Mario Negri Institutional Regulations and Policies (Quality Management System Certificate-UNI EN ISO 9001:2008-Reg N.6121), the NIH Guide for the Care and Use of Laboratory Animals (2011 edition), and EU directives and guidelines (EEC Council Directive 2010/63/UE). We performed experiments with randomization and blinding of the researchers ${ }^{22}$. 


\section{Inflammatory response}

To assess brain inflammation, we injected (26G needle, $0.5 \mu \mathrm{L} / \mathrm{min}$; CMA 400 Syringe Pump, CMA Microdialysis $\mathrm{AB}$, Kista, Sweden) 8-week-old male $\mathrm{C} 57 \mathrm{Bl} / 6 \mathrm{~N}$ mice (Charles River Laboratories) in the striatum (Anteroposterior $=1.0$, Medio-lateral $=2.0$, Dorsoventral $=-2.8$ ) with $5 \mu \mathrm{L}$ unloaded or Tat-Hsp70-loaded composites. On days 3 and 7, we perfused the mice with $4 \%$ paraformaldehyde and processed the brain tissue for immunohistochemical analysis. We cut coronal sections $(30 \mu \mathrm{m}$ thick) on a cryostat, stained for glial fibrillary acidic protein (GFAP; astrocyte marker, 1:3500; EMD Millipore) and CD11b (microglial marker; 1:1000; AbD Serotec, Raleigh, NC, USA) amplified with 3,3'-diaminobenzidine (DAB) staining, and analyzed using ImageJ software by recording the number and the area covered by positive cells at $\times 20$ magnification. We normalized the results to the contralateral hemisphere injected with $5 \mu \mathrm{L}$ PBS.

\section{Composite degradation}

We assessed composite degradation in brain by magnetic resonance imaging (MRI, Bruker-BioSpin, Ettlingen, Germany). We injected (26G needle, $0.5 \mu \mathrm{L} / \mathrm{min}$ ) 8-weekold male $\mathrm{C} 57 \mathrm{Bl} / 6 \mathrm{~N}$ mice in the striatum with $5 \mu \mathrm{L}$ unloaded composites and checked after $4 \mathrm{~h}$ and 1, 2, 4, and 7 days. As a control, we injected the contralateral hemisphere with $5 \mu \mathrm{L}$ PBS.

\section{Tat-Hsp70 release}

To assess the amount of Tat-Hsp70 released from COLL-LMW HA composites in the striatum, we injected 8-week-old male C57Bl/6N mice (26G needle, $0.5 \mu \mathrm{L} /$ min) with $5 \mu \mathrm{L}$ Tat-Hsp70-loaded composites $(1.75 \mu \mathrm{g}$ Tat-Hsp70), while the contralateral hemisphere received $1.75 \mu \mathrm{g}$ free Tat-Hsp70. After $4 \mathrm{~h}$ and 1, 2, 4, and 7 days, we perfused the mice and processed the brain tissue for immunohistochemical analysis. We cut coronal sections (30 $\mu \mathrm{m}$ thick) and stained them by incubation with antiHis tag antibody (1:500; Abcam, Cambridge, UK). After amplification with DAB staining, we analyzed this immunoreactivity with ImageJ software. We normalized the results to the area of the striatum.

\section{Neuroprotection of Tat-Hsp70-loaded composites in a mouse model of PD}

To assess the efficacy of the prototype in a 6-OHDAinduced model of $\mathrm{PD}$, we implanted 7-week-old male C57Bl/6N mice with a unilateral intrastriatal cannula (21G needle). One week later, we injected (26G needle, $0.5 \mu \mathrm{L} / \mathrm{min}$ ) $5 \mu \mathrm{L}$ saline, Tat-Hsp70-loaded composites, or Tat-Hsp70 (1.75 $\mu \mathrm{g}$ Tat-Hsp70). On day 3 we injected $5 \mu \mathrm{L}$ saline or 6 -OHDA $(4 \mu \mathrm{g})$ and 3 days later we repeated the injections of Tat-Hsp70-loaded composites, TatHsp70, or saline. We considered the following groups:
GROUP 1: $5 \mu \mathrm{L}$ Tat-Hsp70-loaded composites $+4 \mu \mathrm{g} 6$ OHDA $+5 \mu \mathrm{L}$ Tat-Hsp70-loaded composites

GROUP 2: $5 \mu \mathrm{L}$ Tat-Hsp70-loaded composites $+5 \mu \mathrm{L}$ saline $+5 \mu \mathrm{L}$ Tat-Hsp70-loaded composites

GROUP 3: $5 \mu \mathrm{L}$ Tat-Hsp70 $+4 \mu \mathrm{g}$ 6-OHDA $+5 \mu \mathrm{L}$ TatHsp70

GROUP 4: $5 \mu \mathrm{L}$ Tat-Hsp70 $+5 \mu \mathrm{L}$ saline $+5 \mu \mathrm{L}$ TatHsp70

GROUP 5: $5 \mu \mathrm{L}$ saline $+4 \mu \mathrm{g}$ 6-OHDA $+5 \mu \mathrm{L}$ saline

GROUP 6: $5 \mu \mathrm{L}$ saline $+5 \mu \mathrm{L}$ saline $+5 \mu \mathrm{L}$ saline

On day 10, we processed brain tissue for immunohistochemical analysis. We stained at least three serial coronal sections covering the substantia nigra for TH (1:300) and analyzed using Image J software by recording the number of positive cells at $\times 20$ magnification. For each mouse, we counted at least $200 \mathrm{TH}$-positive neurons. We normalized the results to the contralateral hemisphere.

\section{Statistics}

We reported the results as mean $\pm \mathrm{SD}$ and analyzed the data with GraphPadPrism software (GraphPad Software, Inc.). We used two-way repeated-measures analysis of variance (ANOVA) followed by Bonferroni's multiple comparisons test for comparisons of the groups and time frames, and one-way ANOVA followed by Tukey's multiple comparison test for comparisons among groups. We set the significance level at 0.05 .

\section{Results}

Biochemical and biological characterization of Hsp70 and Tat-Hsp70

We expressed Hsp70 and Tat-Hsp70 in Escherichia coli and purified them using a single chromatographic step on a HiTrap Chelating column with a yield of 37 and $6.3 \mathrm{mg}$ purified protein/L fermentation broth, respectively. SDSpolyacrylamide gel electrophoresis analysis showed that we produced both proteins with a high degree of purity $(\geq 95 \%)$ (Supplementary Material S2, Section 1, Fig. 1a).

The circular dichroism spectra in the far-UV range were similar for Hsp70 and Tat-Hsp70 (Supplementary Material S2, Section 1, Fig. 1b), indicating that the Tat sequence does not influence the Hsp70 secondary structure.

Both recombinant proteins were folded and active. The specific activities were $(14.85 \pm 1.40)$ and $(14.63 \pm 0.95)$ nmol phosphate/min.mg protein for Tat-Hsp70 and Hsp70, respectively. These figures agree with the value reported for Hsp70 from Plasmodium falciparum $(14.6 \mathrm{nmol} \text { phosphate/min } \cdot \mathrm{mg})^{23}$.

To test the neuroprotective activity of Hsp70 and TatHsp70, we set up a cellular model relevant to PD. SHSY5Y cell metabolic activity was reduced after exposure to the dopaminergic toxin 6-OHDA $\left({ }^{* * * * *} p<0.001\right)$. The reduction was comparable to that of classical oxidative treatment with $\mathrm{H}_{2} \mathrm{O}_{2}$. In both cases, bright-field 
A.

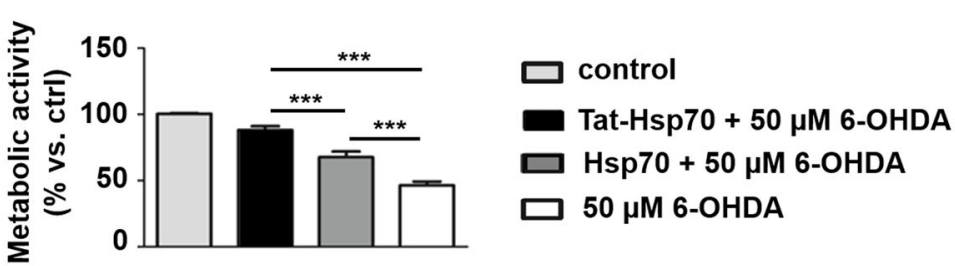

B.
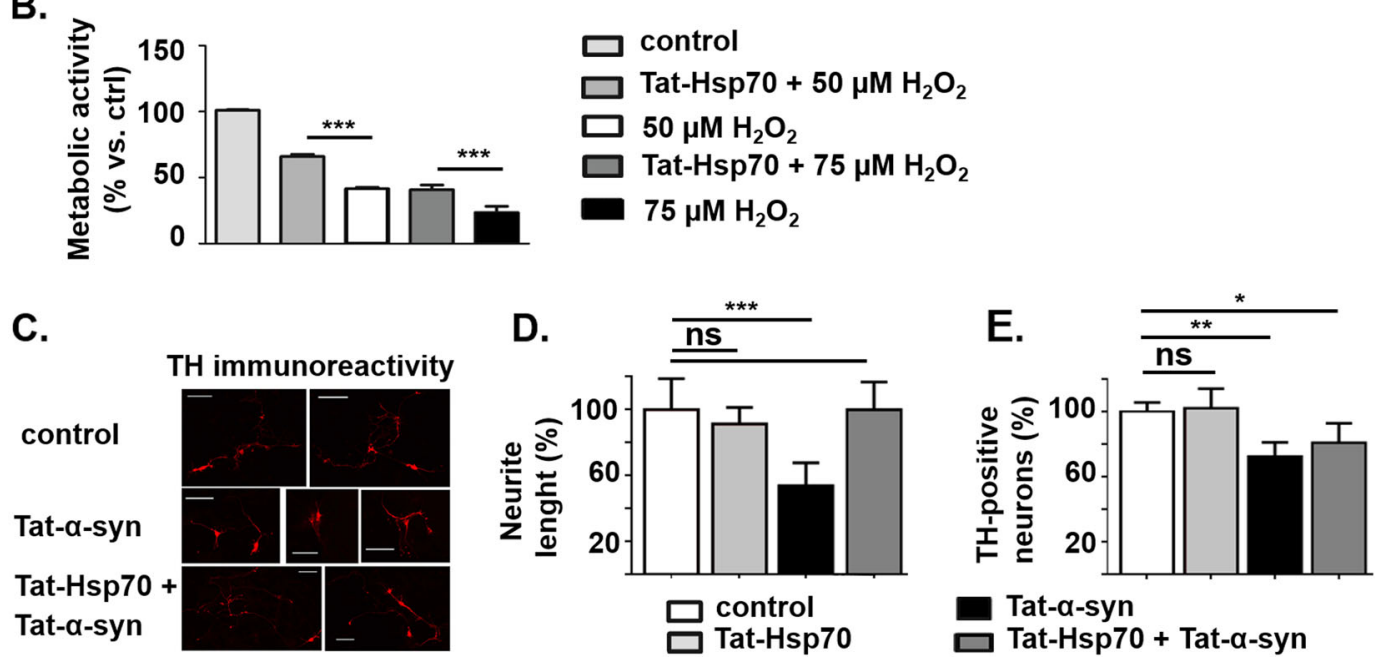

Fig. 1 Biological characterization of Hsp70 and Tat-Hsp70. a SH-SY5Y cell metabolic activity after $2 \mathrm{~h}$ treatment with $250 \mathrm{nM}$ Tat-Hsp70 or Hsp70, and $24 \mathrm{~h}$ incubation with $50 \mathrm{\mu M}$ 6-OHDA. Results from resazurin assay, 13 replicates/group. After incubation with $250 \mathrm{nM}$ Tat-Hsp70 or Hsp70 only, SH-SY5Y cell metabolic activity was comparable to that of controls ( $p>0.05$, data not shown). $\mathbf{b}$ SH-SY5Y cell metabolic activity after $2 \mathrm{~h}$ treatment with $250 \mathrm{nM}$ Tat-Hsp70 and $24 \mathrm{~h}$ incubation with $\mathrm{H}_{2} \mathrm{O}_{2}(50,75 \mu \mathrm{M})$. Results from resazurin assay, 9 replicates/group. c Mesencephalic neurons from CD-1 fetal mice stained for dopaminergic marker TH after $3 \mathrm{~h}$ treatment with $250 \mathrm{nM}$ Tat-Hsp70 and $24 \mathrm{~h}$ incubation with $3 \mu \mathrm{M}$ Tat-a-syn. Scale bar $=$ $100 \mu \mathrm{m}, 4$ replicates/group. d Average length of principal neurite normalized to control in standard medium. We counted at least 100 neurons/ group. e Number of TH-positive neurons normalized to controls in standard medium. We counted at least 100 neurons/group. Results are presented as mean \pm SD. We analyzed the results with one-way ANOVA followed by Tukey's multiple comparisons test. ${ }^{*} p<0.05 ;{ }^{* *} p<0.01 ;{ }^{* * *} p<0.001$

microscopy images showed an increase in the number of roundish and dead cells with increasing toxic stimuli concentration (Supplementary Material S2, Section 2.1, Fig. 2).

For confirmation of the activity of purified recombinant proteins, we observed a neuroprotective effect when incubating SH-SY5Y cells with Tat-Hsp70 or Hsp70 before exposure to $50 \mu \mathrm{M}$ 6-OHDA $(* \cdots * 0.001$, Fig. 1a). Neuroprotection was greater for Tat-Hsp70 $(* * * 0<0.001)$, likely because of its Tat-mediated cell-penetrating activity. Nagel et al. ${ }^{24}$ demonstrated the ability of Tat-Hsp70 to penetrate cell membranes and we replicated this result with our Tat-Hsp70 preparation. For this reason, and with a view toward in vivo application, we performed further experiments with Tat-Hsp70 only. This recombinant protein protected SH-SY5Y cells from the effects of exposure to 50 or $75 \mu \mathrm{M} \mathrm{H}_{2} \mathrm{O}_{2}\left({ }^{* * * *} p<0.001\right.$, Fig. 1b). We confirmed the neuroprotective effect after challenging the primary mesencephalic neurons with the aggregationprone protein $\alpha$-syn, a molecular player in $\mathrm{PD}^{3}$ (Fig. 1c).
Pretreatment with Tat-Hsp70 recovered the mean length of the principal neurite of TH-positive cells (Fig. 1d) and the number of $\mathrm{TH}$-positive dopaminergic neurons was only slightly higher (Fig. 1e).

\section{Hydrogel characterization}

Small amplitude shear tests showed that $G^{\prime}$ values were always greater than $G^{\prime \prime}$ values (Fig. 2a). In the investigated frequency range, $G^{\prime}$ was practically constant for COLL $((2.3 \pm 0.2) \mathrm{Pa})$ and COLL-LMW HA $((3.7 \pm 0.4) \mathrm{Pa})$, and we achieved higher values (from $(9.8 \pm 0.8) \mathrm{Pa}$ to $(14.8 \pm$ 1.3) $\mathrm{Pa}$ ) for COLL-HMW HA as the frequency increased from 0.01 to $2 \mathrm{~Hz}$. Steady shear measurements (Fig. 2b) indicated shear-thinning behavior, supporting the possibility of successfully injecting the materials.

Compared with COLL gels, the presence of HA supplied higher values of viscosity and this effect was dependent on HA molecular weight. As the shear rate increased, viscosity varied from (5.7 \pm 0.7$)$ Pa.s to $\left(1.3 \times 10^{-3} \pm 0.1 \times 10^{-3}\right) \mathrm{Pa} \cdot \mathrm{s}$ for COLL, from $(25.9 \pm 3.9)$ Pa.s to $\left(4.7 \times 10^{-3} \pm 0.5 \times\right.$ 

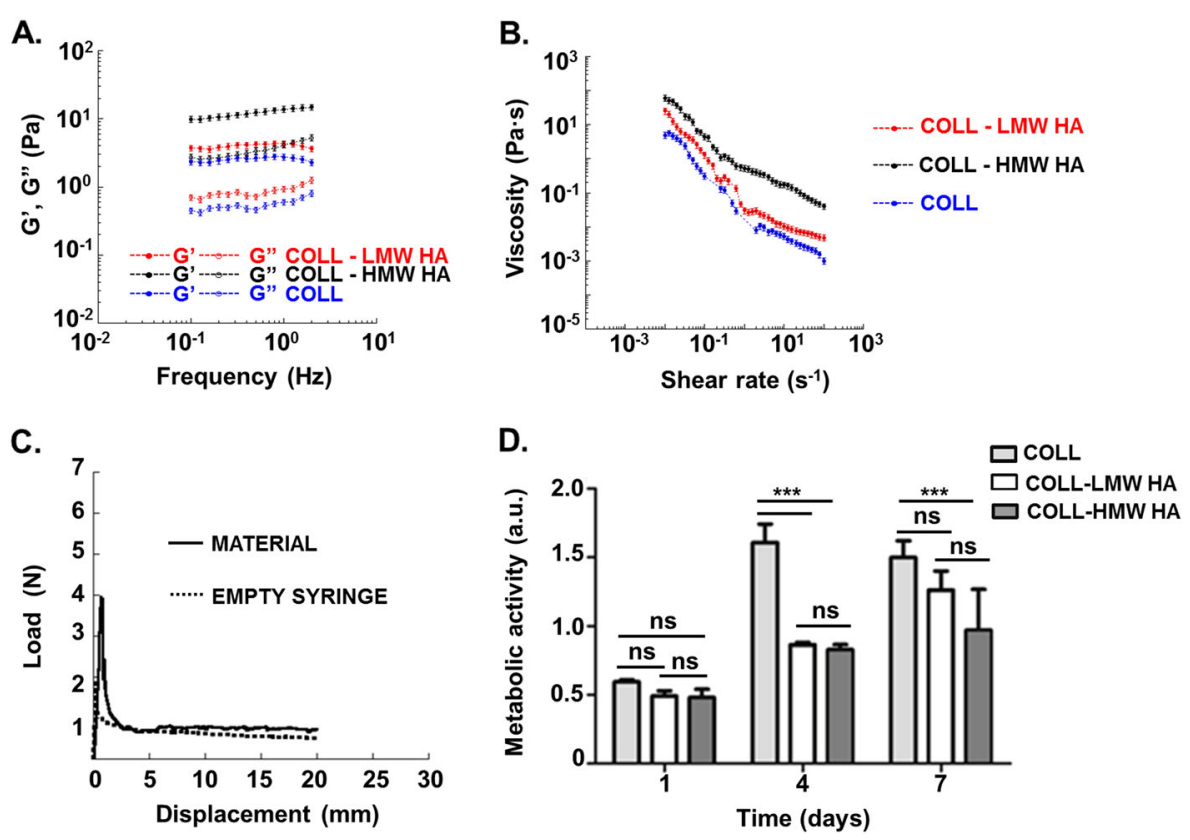

Fig. 2 Rheological and biological characterization of hydrogels. a Small amplitude oscillatory shear tests: storage modulus ( $\left.G^{\prime}\right)$ and loss modulus $\left(G^{\prime \prime}\right)$ as a function of frequency for COLL, COLL-LMW HA, and COLL-HMW HA gels, 3 replicates/group. b Steady shear tests: viscosity as a function of shear rate for COLL, COLL-LMW HA, and COLL-HMW HA gels, 3 replicates/group. c Injectability tests: typical load-displacement curves for gel-based systems injected through a 30G needle (solid line) or an empty syringe (dotted line). d SH-SY5Y cell metabolic activity with time after embedding in COLL, COLL-LMW HA, and COLL-HMW HA gels. The results from MTS assay, 6 replicates/group. We analyzed the results with two-way ANOVA followed by Bonferroni's multiple comparisons test. ns, $p>0.05 ;{ }^{*} p<0.05 ;{ }^{* *} p<0.001$. Results are presented as mean \pm SD

$\left.10^{-3}\right)$ Pa.s for COLL-LMW HA, and from $(61.2 \pm 9.2)$ Pa.s to $\left(4.0 \times 10^{-2} \pm 0.5 \times 10^{-2}\right)$ Pa.s for COLL-HMW HA.

Injectability tests indicated that the proposed materials were easily injectable into and through a $30 \mathrm{G}$ needle. The materials produced similar load-displacement curves (Fig. 2c). After an initial linear region, the load peaked before decreasing to a plateau-like region, by the end of which the materials were completely injected. The maximum and plateau loads (Table 1) for COLL-HMW HA were greater than those of COLL-LMW HA gels, suggesting an effect of the HA molecular weight.

For ultrastructural and structural analysis of COLL-HA networks, please refer to Supplementary Material S2, Section 3, Fig. 3.

After embedding, SH-SY5Y cell metabolic activity (Fig. 2d) increased from day 1 to 7 in COLL-LMW HA semi-IPNs, whereas for COLL and COLL-HMW HA gels this effect occurred only between days 1 and 4. On day 1 , we did not observe differences among the materials (ns, $p$ $>0.05$ ). On day 4 , cell metabolic activity was greater in COLL than in COLL-HA gels $(* * * * 0<0.001)$. On day 7 , cell metabolic activity was comparable in COLL and COLLLMW HA gels (ns, $p>0.05$ ), but in COLL-HMW HA semi-IPNs it was lower than in COLL gels $(* * * * 0<0.001)$.

\section{Particle characterization}

NTA showed that particles were spherical in shape (Supplementary Material S2, Section 4.1 and Video 4) with a hydrodynamic size of $(237.0 \pm 58.8) \mathrm{nm}$ (Fig. 3a). These results agree with the morphology suggested by SEM (Fig. 3b) and the average size $((157.2 \pm 37.5) \mathrm{nm})$ measured by dynamic light scattering. After $24 \mathrm{~h}$ (Fig. 3c) or $72 \mathrm{~h}$ incubation (Fig. 3d) with particles, cell metabolic activity was comparable to that of controls (ns, $p>0.05$ ). Observation of cell nuclei and F-actin filaments indicated physiological cellular substructures together with healthy cell morphology, as confirmed by the presence of extended protruding neuritis (Supplementary Material S2, Section 4.2, Fig. 5a, b).

\section{Rheological and biological characterization of Tat-Hsp70- loaded composites}

Small amplitude shear tests showed that $G^{\prime}$ values were always greater than $G^{\prime \prime}$ values (results for COLL-LMW HA composites are shown in Fig. $4 \mathrm{a}, \mathrm{b}$ ), and the inclusion of particles influenced both dynamic moduli. In the investigated frequency range, $G^{\prime}$ values were $(4.1 \pm 0.4)$, $(5.3 \pm 0.5)$, and $(3.3 \pm 0.3)$ Pa for COLL-LMW HA semiIPNs with 10,25 , and $50 \mu \mathrm{g} / \mathrm{mL}$ particles, respectively. 
Table 1 Maximum and plateau loads to inject the hydrogel-based systems through a 30G needle

\begin{tabular}{lll}
\hline Material & Maximum load $(\boldsymbol{N})$ & Plateau load $(\boldsymbol{N})$ \\
\hline Empty syringe & $1.6 \pm 0.3$ & $0.6 \pm 0.1$ \\
COLL gels & $3.4 \pm 0.5$ & $0.9 \pm 0.1$ \\
COLL-LMW HA semi-IPNs & $3.9 \pm 0.4$ & $2.9 \pm 0.1$ \\
COLL-HMW HA semi-IPNs & $6.8 \pm 0.7$ & $1.0 \pm 0.1$ \\
COLL-LMW HA semi-IPNs $+10 \mu \mathrm{g} / \mathrm{mL}$ particles & $4.2 \pm 0.4$ & $1.2 \pm 0.1$ \\
COLL-LMW HA semi-IPNs $+25 \mu \mathrm{g} / \mathrm{mL}$ particles & $4.3 \pm 0.4$ & $0.9 \pm 0.1$ \\
COLL-LMW HA semi-IPNs $+50 \mu \mathrm{g} / \mathrm{mL}$ particles & $3.7 \pm 0.5$ & $2.2 \pm 0.2$ \\
COLL-HMW HA semi-IPNs $+10 \mu \mathrm{g} / \mathrm{mL}$ particles & $7.1 \pm 0.6$ & $2.3 \pm 0.3$ \\
COLL-HMW HA semi-IPNs $+25 \mu \mathrm{g} / \mathrm{mL}$ particles & $7.0 \pm 0.5$ & $2.0 \pm 0.3$ \\
COLL-HMW HA semi-IPNs $+50 \mu \mathrm{g} / \mathrm{mL}$ particles & $6.5 \pm 0.6$ & $1.0 \pm 0.1$ \\
COLL-LMW HA semi-IPNs $+25 \mu \mathrm{g} / \mathrm{mL}$ particles $+0.35 \mu \mathrm{g} / \mathrm{mL}$ Tat-Hsp70 & $4.0 \pm 0.5$ & \\
\hline
\end{tabular}

We selected COLL-LMW HA semi-IPNs loaded with $25 \mu \mathrm{g} / \mathrm{mL}$ gelatin particles. As delivery prototypes, we selected COLL-LMW HA semi-IPNs loaded with gelatin particles $(25 \mu \mathrm{g} / \mathrm{mL})$ and Tat-Hsp70 $(0.35 \mu \mathrm{g} / \mathrm{mL})$. Results are mean $\pm \mathrm{SD}, 3$ replicates/group

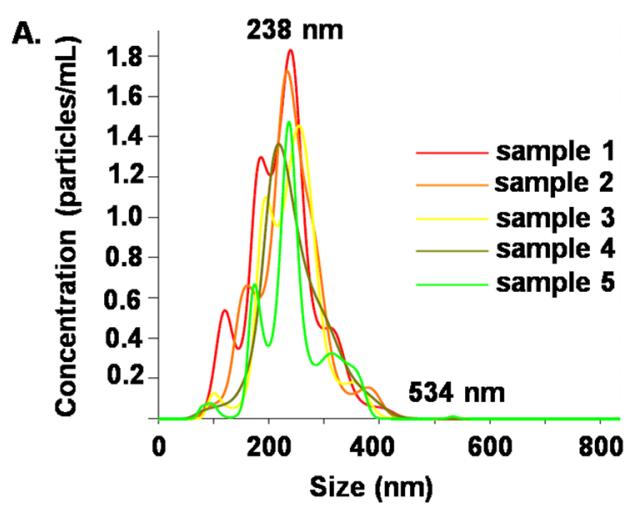

C.

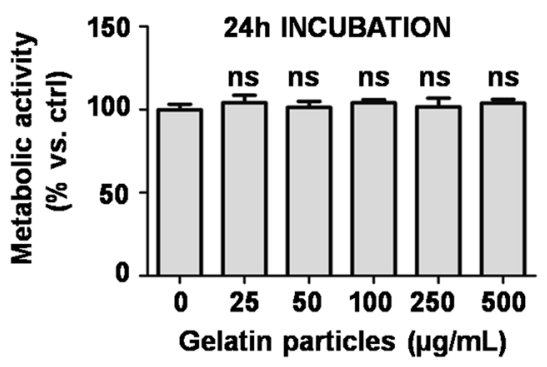

B.

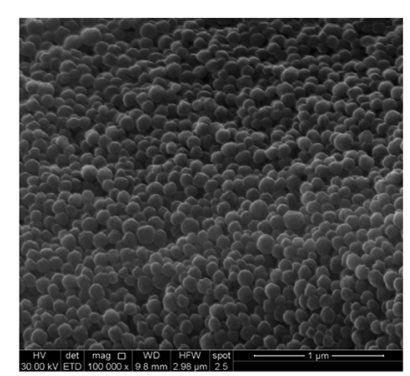

D.

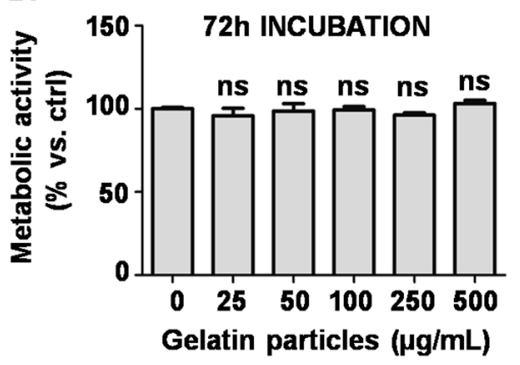

Fig. 3 Particle characterization. a Results from NTA: particle concentration as a function of hydrodynamic size (5 replicates indicated as sample 1, sample 2, sample 3, sample 4, and sample 5). b Particle morphology by SEM, scale bar $=1 \mu \mathrm{m}$. SH-SY5Y cell metabolic activity after incubation with gelatin particles for $\mathbf{c} 24 \mathrm{~h}$ and $\mathbf{d} 72 \mathrm{~h}$. Results (mean \pm SD) from resazurin assay, 5 replicates/group. We compared the results to controls in standard medium with one-way ANOVA followed by Tukey's multiple comparisons test. ns, $p>0.05$

Steady shear measurements (Fig. 4c) showed that shearthinning behavior and viscosity values depended on particle concentration. For COLL-LMW HA semi-IPNs with 10,25 , and $50 \mu \mathrm{g} / \mathrm{mL}$ particles, viscosity values ranged from $(305.1 \pm 31.2)$ to $\left(1.1 \times 10^{-2} \pm 0.1 \times 10^{-2}\right) \mathrm{Pa} \cdot \mathrm{s}$, from $(350.0 \pm 43.1)$ to $\left(1.4 \times 10^{-2} \pm 0.1 \times 10^{-2}\right) \mathrm{Pa} \cdot \mathrm{s}$, and from $(140.0 \pm 16.1)$ to $\left(6.1 \times 10^{-3} \pm 0.9 \times 10^{-3}\right) \mathrm{Pa} \cdot \mathrm{s}$, respectively. As $G^{\prime}$ values decreased for particle concentration 
A.

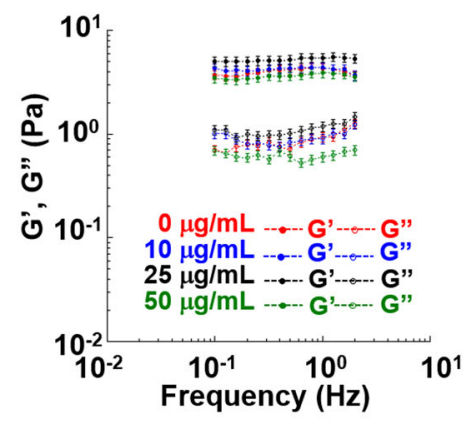

D.

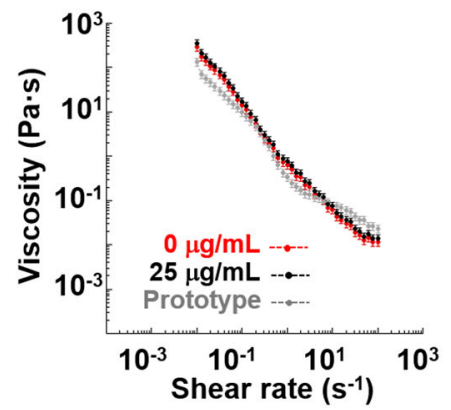

B.

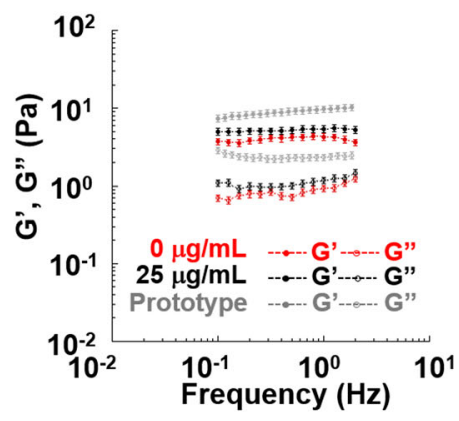

E.

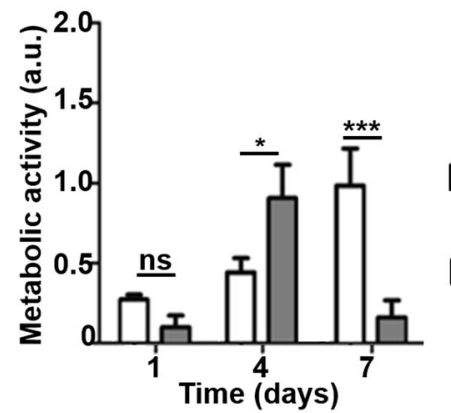

C.

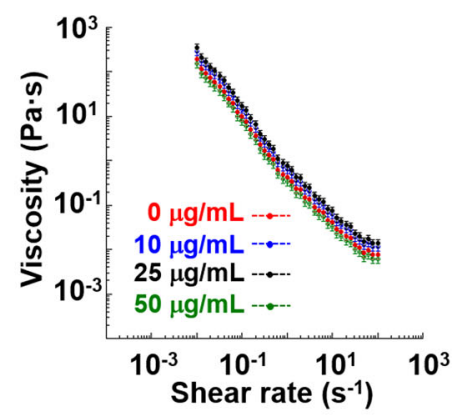

COLL-LMW HA $+25 \mu \mathrm{g} / \mathrm{mL}$ particles

COLL-HMW HA $+25 \mu \mathrm{g} / \mathrm{mL}$ particles

Fig. 4 Characterization of COLL-LMW HA composites. Small amplitude oscillatory shear tests: storage modulus $\left(G^{\prime}\right)$ and loss modulus $\left(G^{\prime \prime}\right)$ as a function of frequency for a COLL-LMW HA gels loaded with 10, 25, and $50 \mu \mathrm{g} / \mathrm{mL}$ particles, 3 replicates/group. b Device prototypes (COLL-LMW HA loaded with $25 \mu \mathrm{g} / \mathrm{mL}$ particles and $0.35 \mu \mathrm{g} / \mathrm{mL}$ Tat-Hsp70), 3 replicates/group. Steady shear tests: viscosity as a function of shear rate for c COLLLMW HA gels loaded with 10, 25, and $50 \mu \mathrm{g} / \mathrm{mL}$ particles, 3 replicates/group. d Device prototypes (COLL-LMW HA loaded with $25 \mu \mathrm{g} / \mathrm{mL}$ particles and $0.35 \mathrm{\mu g} / \mathrm{mL}$ Tat-Hsp70), 3 replicates/group. e SH-SY5Y cell metabolic activity with time after embedding in COLL-LMW HA and COLL-HMW HA composites (both loaded with $25 \mu \mathrm{g} / \mathrm{mL}$ particles). Results from MTS assay, 6 replicates/group. We analyzed the results with two-way ANOVA followed by Bonferroni's multiple comparisons test. ns, $p>0.05 ;{ }^{*} p<0.05 ;{ }^{* *} p<0.001$. Results are presented as mean \pm SD

above $25 \mu \mathrm{g} / \mathrm{mL}$, we selected a final particle concentration of $25 \mu \mathrm{g} / \mathrm{mL}$.

After loading Tat-Hsp70 in the selected COLL-LMW HA composites, $G^{\prime}$ values increased from $(7.8 \pm 0.8)$ to $(10.5 \pm 1.1) \mathrm{Pa}$ in the investigated frequency range (Fig. $4 \mathrm{~b})$. Viscosity varied from $(134.1 \pm 17.9)$ to $\left(2.3 \times 10^{-2} \pm\right.$ $0.3 \times 10^{-2}$ ) Pa.s (Fig. 4d).

Injectability tests confirmed that the inclusion of particles and Tat-Hsp70 did not affect maximum and plateau loads compared with those of the starting formulation (Table 1).

To test the biocompatibility, we embedded SH-SY5Y cells in the selected composites. The metabolic activity (Fig. 4e) increased from day 1 to 7 in the COLL-LMW HA composites, but in COLL-HMW HA composites it decreased between days 4 and 7 . On day 1 , we did not find differences between the materials (ns, $p>0.05$ ). On day 4 , cell metabolic activity was greater in COLL-HMW HA than in COLL-LMW HA composites $(" p<0.05)$. On day 7 , the pattern was reversed, with COLL-LMW HA composites showing better results $\left({ }^{* * * *} p<0.001\right)$. For this reason, we selected COLL-LMW HA composites for the development of the delivery system.

We assessed the release of Tat-Hsp70 by silver staining (Fig. 5a), the sensitivity of which is in the low nanogram range. For each time point, we estimated the intensity of protein bands using a calibration line based on five standards (an example is shown in Fig. 5b). We found (Fig. 5c) that COLL-LMW HA composites released $~ 5 \%$ of the loaded Tat-Hsp70 after $1 \mathrm{~h}, 16 \%$ after $4 \mathrm{~h}, 41 \%$ after $24 \mathrm{~h}, 87 \%$ after $72 \mathrm{~h}$, and $95 \%$ after $96 \mathrm{~h}$ (mean values). Tat-Hsp70 fragments with a molecular weight lower than $75 \mathrm{kDa}$ became visible in selected samples only after $96 \mathrm{~h}$, suggesting protein degradation.

We determined the release mechanism by fitting the in vitro release profile with various release kinetic models. We achieved the best results with the Korsmeyer-Peppas model $\left(\frac{M_{t}}{M_{\infty}}=K t^{n}\right.$; Fig. $\left.5 \mathrm{~d}\right)$, where $\frac{M_{t}}{M_{\infty}}$ is the fraction of TatHsp70 released at time $t, K$ is the release rate constant, and $n$ is the diffusional exponent. We performed linear regression analysis and calculated $n=0.60 \pm 0.04$, suggesting both diffusional and relaxational transport due to matrix swelling. 


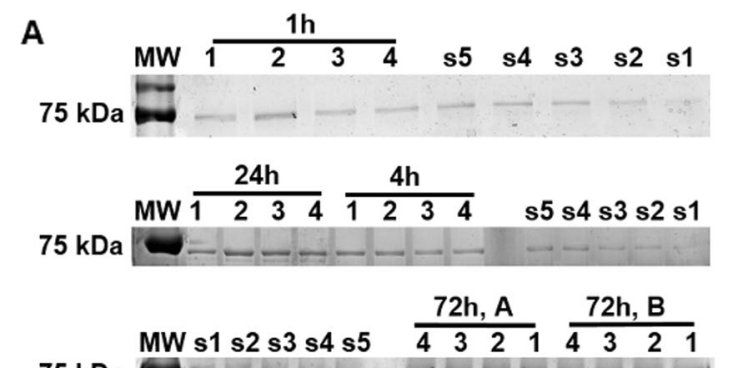

$75 \mathrm{kDa}$

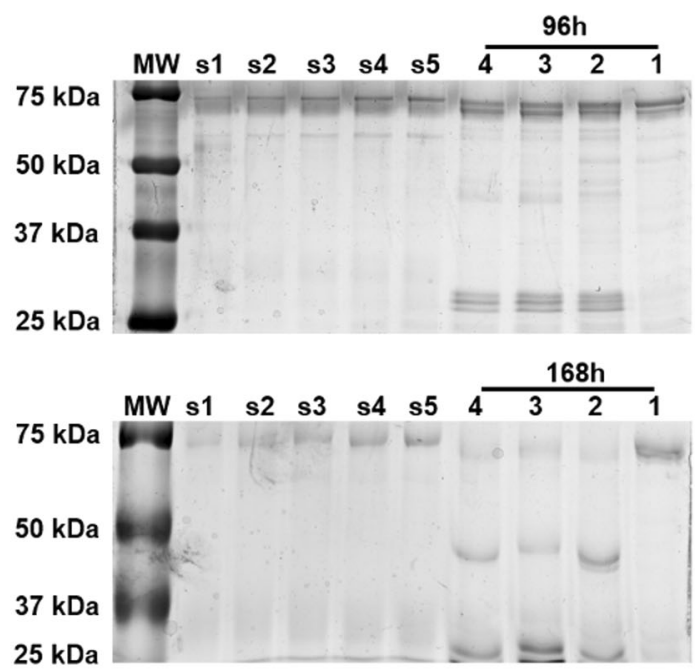

B

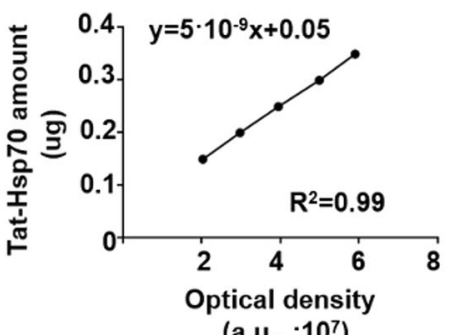

C

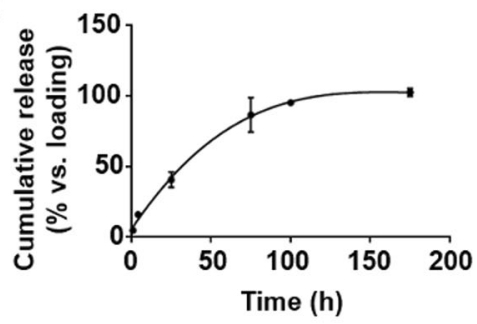

D

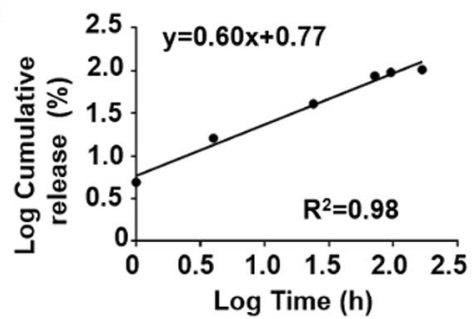

Fig. 5 In vitro Tat-Hsp70 release from COLL-LMW HA composites. a After electrophoretic separation on $8 \%$ gradient polyacrylamide gels, we performed silver staining on the supernatants collected from Tat-Hsp70-loaded composites (4 replicates: 1, 2, 3, 4) in PBS after 1, 4, 24, 72, 96, and $168 \mathrm{~h}$ (7 days). For each gel, we used five standards ( $s 1=0.15 \mu \mathrm{g} ; \mathrm{s} 2=0.2 \mu \mathrm{g} ; \mathrm{s} 3=0.25 \mu \mathrm{g} ; \mathrm{s} 4=0.3 \mu \mathrm{g} ; \mathrm{s} 5=0.35 \mu \mathrm{g}$ ) and loaded 35, 19, 12, 10, 15, 55, and $55 \mu \mathrm{L}$ supernatants collected after 1, 4, 24, 72 (A), 72 (B), 96, and 168 h, respectively. $\mathbf{b}$ Example of a calibration line used to estimate the amount of Tat-Hsp70 from the optical density of the bands visualized by silver staining. c Release profile of Tat-Hsp70 in PBS. We reported the results as percentages with respect to the initial protein loading $(175 \mu \mathrm{g})$. Vertical bars represent mean \pm SD (4 replicates). $\mathbf{d}$ Logarithmic plot of cumulative drug release as a function of log of time. Our fitting suggested that the release mechanism follows Korsmeyer-Peppas kinetics $\left(R^{2}=0.98\right)$

We also confirmed the neuroprotective effect of TatHsp70 released from COLL-LMW HA composites (Supplementary Material S2, Section 5.1, Fig. 6) and excluded the involvement of hydrogel degradation products in neuroprotection (Supplementary Material S2, Section 5.2, Fig. 7).

\section{In vivo inflammatory response}

We exploited in vitro studies to select the best composite formulation for the release of biologically active Tat-Hsp70. We assessed the inflammatory response triggered by this composite in vivo, starting from a peripheral model (air pouch). After injecting the basic components, the number of recruited leukocytes (a marker of inflammation, Table 2) was comparable to those of saline, LMW HA solution, COLL gels, COLL-LMW HA semi-IPNs, and COLL-LMW HA composites $(p>0.05)$. Tat-Hsp70- loaded composites recruited more leukocytes (" $p<0.05)$, although this effect was significantly lower than that from ultrapure lipopolysaccharide (positive control, ${ }^{* * * *} p<$ 0.0001).

Three days after injecting unloaded or Tat-Hsp70loaded composites into the striatum, immunohistochemical analysis (Fig. 6a) showed an increase in brain inflammation after treatment with the prototype $\left({ }^{* * * * *} p<\right.$ 0.0001), whereas the results were comparable to those of controls for unloaded composites (ns, $p>0.05$ ). Brain inflammation was reduced on day 7 (Fig. 6b), when the area covered by GFAP-positive cells was comparable to that of controls (ns, $p>0.05$ ) for both unloaded and TatHsp70-loaded composites. On day 7, CD11b levels for Tat-Hsp70-loaded composites were higher than those of the controls (" $p<0.05)$, but they were lower than those on day 3 . 

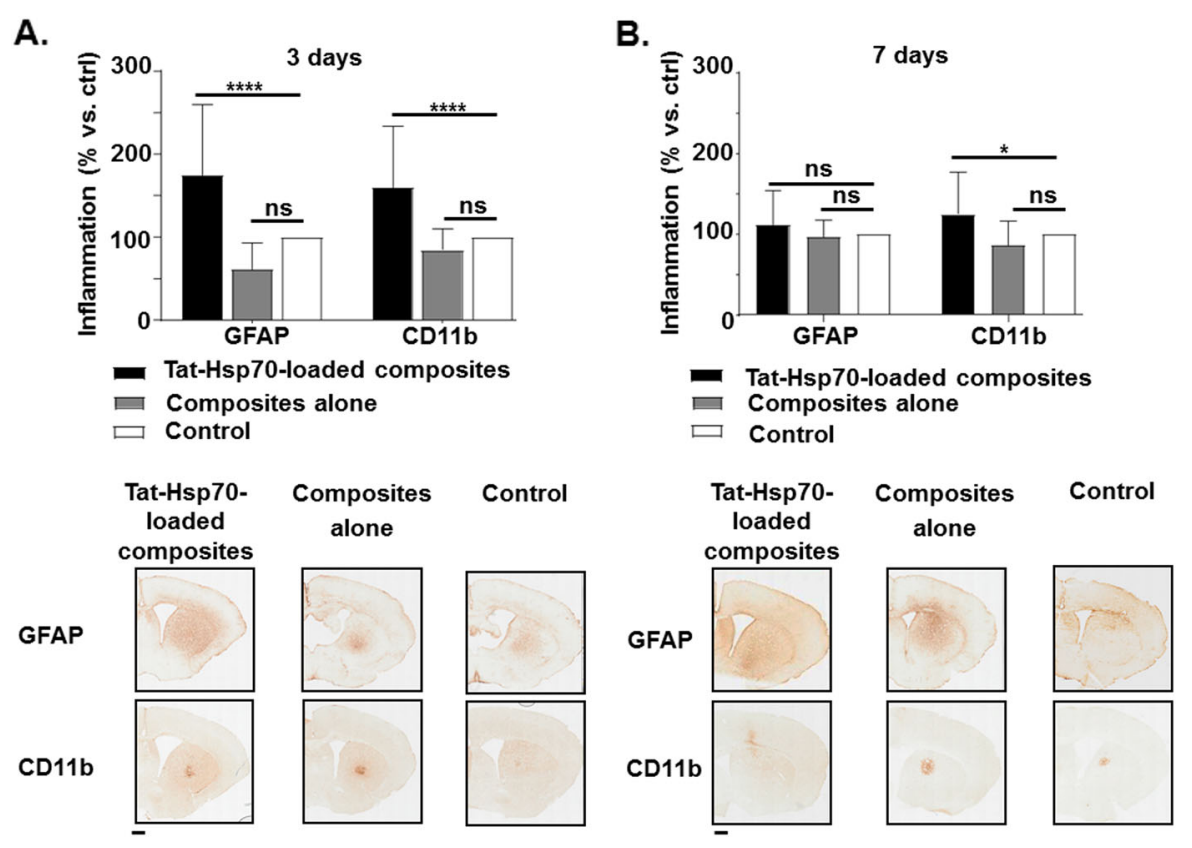

Fig. 6 Inflammatory response after injecting unloaded or Tat-Hsp70-loaded composites into mouse striatum. GFAP and CD $11 \mathrm{~b}$ reactivity and quantitative analysis 3 (a) and 7 (b) days after injecting $5 \mu \mathrm{L}$ Tat-Hsp70-loaded COLL-LMW HA composites, COLL-LMW HA composites, and PBS (control) in mouse striatum (6 mice/group). The bar graph shows the digital quantitative analysis of immunostaining, examples of which are reported for each group in the lower panel. Scale bar $=200 \mu \mathrm{m}$. The results are presented as mean \pm SD. We analyzed the results with one-way ANOVA followed by Tukey's multiple comparisons test. ns, $p>0.05 ;{ }^{*} p<0.05 ;{ }^{* * *} p<0.0001$

\section{Composite degradation in the brain}

As no data are available from the literature, we assessed the degradation time of composites in the brain via longitudinal MRI on living mice. We detected both PBS and COLL-LMW HA composites $4 \mathrm{~h}$ after injection, although the hyperintense signal was more clearly visible at the injection site for the hydrogels (Fig. 7a). We confirmed the presence of composites on days 1 and 2 , and we detected only a few residues on day 4 . We did not detect signs of composites on day 7 . Therefore, once depleted from Tat-Hsp70, hydrogels do not accumulate at the injection site.

\section{Tat-Hsp70 release in the brain}

To assess protein release in the striatum and confirm that hydrogel presence is fundamental to achieving a more spatially focused neuroprotective effect, we injected both free and embedded Tat-Hsp70. Immunohistochemical analysis (Fig. 7b) indicated that after $4 \mathrm{~h}$, both free and embedded proteins were localized to the injection site, whereas after $24 \mathrm{~h}$ they started to diffuse. Free Tat-Hsp70 diffused more rapidly, as shown by the lightening of the brown color. The analysis of His tag immunoreactivity (Fig. 7c) confirmed that after 48 and $96 \mathrm{~h}$ Tat-Hsp70 released from composites is localized on a greater area of target tissue with respect to the free protein $\left({ }^{*} p<0.05\right.$ and
${ }^{* * *} p<0.01$; respectively). In particular, at $96 \mathrm{~h}$ free TatHsp70 was almost depleted. According to the degradation patterns, after 7 days we did not detect any immunoreactivity from Tat-Hsp70-loaded composites.

\section{Neuroprotection of Tat-Hsp70-loaded composites in a mouse model of PD}

We assessed the performance of Tat-Hsp70-loaded composites in an in vivo model of dopaminergic degeneration relevant to PD (Fig. 8). Quantitative analysis of TH immunoreactivity in the substantia nigra (Fig. 8b) indicated that intrastriatal infusion of $4 \mu \mathrm{g} 6$-OHDA depleted dopaminergic neurons by $\sim 30 \%$. In the presence of the toxic stimulus, free Tat-Hsp70 did not convey neuroprotection and gave results comparable to 6-OHDA alone (ns, $p>0.05$ ). In contrast, we noticed a positive response when injecting Tat-Hsp70-loaded composites (******p< 0.0001 ), with results comparable to those of saline.

\section{Behavioral tests}

As the performance depends on an intact nigrostriatal pathway, the Rotarod test is sensitive for detection of graded improvements or deterioration of motor functions. The results (Fig. 8c) showed that 6-OHDA impaired motor functions with respect to PBS $(* p<0.01)$, but injection of free Tat-Hsp70 or Tat-Hsp70-loaded 
A.
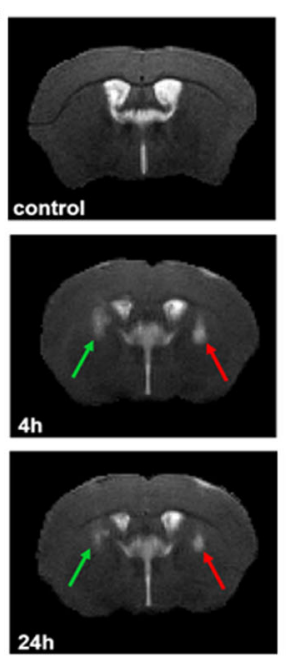

C.

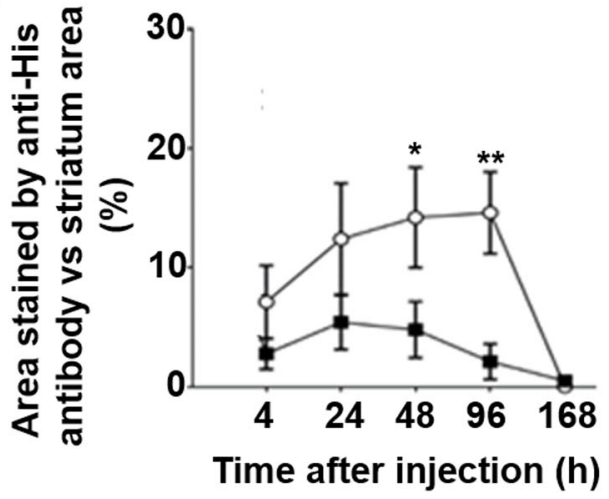

B.
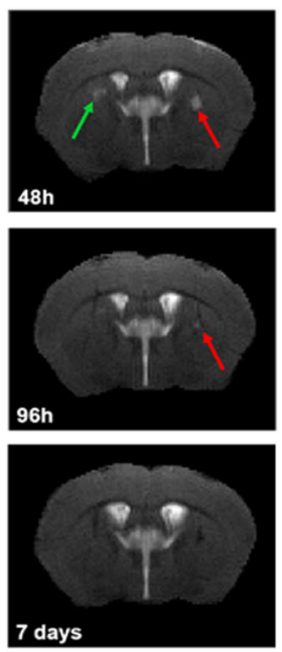
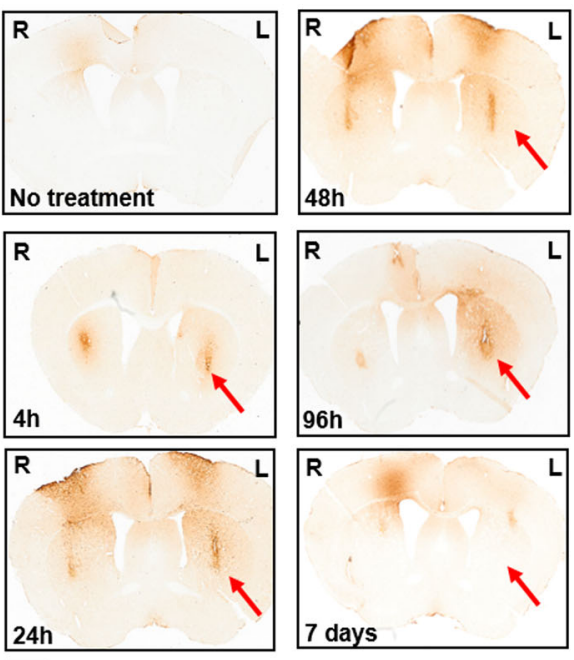

\section{$\approx$ Tat-Hsp70-loaded composites \\ - Free Tat-Hsp70}

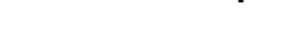

Fig. 7 Live magnetic resonance imaging (MRI) to follow time patterns of degradation of COLL-LMW HA composites and Tat-Hsp70 release in the brain. a Representative MRI images of the fates of PBS and COLL-LMW HA composites after injection in mouse striatum. Slice thickness: $0.5 \mathrm{~mm}$, in plane resolution: $0.1 \times 0.1 \mathrm{~mm}^{2}$. We scanned the same mouse $4 \mathrm{~h}$ and 1, 2, 4, and 7 days after surgery. The scan labeled as control is the same mouse before surgery. We highlighted brain areas injected with PBS by green arrows and areas injected with COLL-LMW HA composites by red arrows. We replicated the experiment in four independent animals with similar results. $\mathbf{b}$ His tag immunoreactivity $4 \mathrm{~h}$ and $1,2,4$, and 7 days after injecting $5 \mu \mathrm{L}$ Tat-Hsp70-loaded COLL-LMW HA composites in the left ( $\mathrm{L}$, indicated by red arrows) hemisphere and $5 \mu \mathrm{L}$ free Tat-Hsp70 in the right (R) hemisphere (4 mice/group). Scale bar $=200 \mu \mathrm{m}$. c Quantitative analysis of His tag immunoreactivity. We normalized the results (mean \pm SD) to the area of the striatum. We analyzed the results with one-way ANOVA followed by Tukey's multiple comparisons test. ${ }^{*} p<0.05$; ${ }^{* *} p<0.01$

composites allowed for recovery. In both cases, the latency period to fall was comparable to that of PBS (ns, $p$ $>0.05$ ). We did not observe differences between free TatHsp70 and Tat-Hsp70-loaded composites (ns, $p>0.05$ ).

For an independent confirmation of the previous results, we performed the beam walk test ${ }^{25}$ (Fig. 8d). With respect to $\mathrm{PBS}$, we observed the highest number of falls $\left({ }^{* * * * * *} p<0.0001\right)$ and measured the longest time to complete the narrow path (data not shown) for mice treated with 6-OHDA. Again, the injection of free Tat-Hsp70 or Tat-Hsp70-loaded composites allowed for recovery. We did not find differences between free Tat-Hsp70 and TatHsp70-loaded composites, but the mean value of falls was lower for mice injected with Tat-Hsp70-loaded composites than for mice injected with the free protein $(p=$ 0.06). As an example, we uploaded a movie showing one animal/group performing the beam walk (Supplementary Material S3 and Video S3).

\section{Discussion}

This study aimed to develop a biocompatible, biodegradable, and injectable Hsp70 delivery system as a starting point for therapeutic approaches to PD and other chronic neurodegenerative disorders. As no similar systems currently exist for the CNS, a first innovation lies in the proposed approach. 
Table 2 Inflammatory response of the basic components and the assembled prototype for Tat-Hsp70 delivery evaluated as leukocyte recruitment in the air pouch model

Treatment

Number of leukocytes

$\left(\cdot 10^{6}\right)$

\begin{tabular}{ll}
\hline COLL gels & $0.32 \pm 0.15$ \\
LMW HA solution & $0.65 \pm 0.18$ \\
COLL-LMW HA semi-IPNs & $0.26 \pm 0.08$ \\
COLL-LMW HA semi-IPNs $+25 \mu \mathrm{g} / \mathrm{mL}$ & $0.28 \pm 0.19$ \\
particles & \\
COLL-LMW HA semi-IPNs $+25 \mu \mathrm{g} / \mathrm{mL}$ & $2.37 \pm 0.60^{*}$ \\
particles $+0.35 \mu \mathrm{g} / \mathrm{mL}$ Tat-Hsp70 & \\
Saline & $0.34 \pm 0.17$ \\
$0.5 \mu \mathrm{g}$ Ultra-pure lipopolysaccharide & $11.3 \pm 3.0^{* * * *}$ \\
\hline
\end{tabular}

We created subcutaneous dorsal pouches in CD-1 mice and injected with the materials (previously kept at $37^{\circ} \mathrm{C}$ for $1 \mathrm{~h}$ ), saline (negative control), or lipopolysaccharide (positive control), as described in Methods. After collecting the exudates, we stained leukocytes with Trypan blue dye and counted. Results are mean $\pm S D, 5$ mice/group. We analyzed the results with one-way ANOVA followed by Tukey's multiple comparisons test. ${ }^{*} p<0.05$; ${ }^{* * *} p<0.0001$

We started from the following key points: (1) the neuroprotective effect of Hsp70 in PD models ${ }^{14,26,27}$; (2) the efficacy of cell-penetrating peptides (e.g., Tat sequence) in delivering active proteins across biological membranes ${ }^{28}$; (3) the advantages of injectable and resorbable hydrogels for drug delivery ${ }^{29}$; and (4) the use of gelatin particles to avoid a decrease in $G^{\prime}$ values and alteration of rheological behavior after injection ${ }^{20}$, as well as a possible element to modulate Hsp70 release. To demonstrate the effectiveness of this strategy and directly target the PD-involved neurodegenerative brain region, we assessed the properties and performances of both basic components and the final prototype in vitro and in vivo by striatal injection. We realize that this approach currently requires an invasive surgical procedure. However, miniaturized injection needles and less invasive surgical/delivery protocols might reduce tissue damage. For instance, epi-cortical delivery has attracted considerable attention, but protein diffusion through brain tissue is still limited for applications in humans ${ }^{30,31}$, although in this respect the Tat-fusion strategy might help. The rationale of this approach is to create a biocompatible hydrogel reservoir (i.e., our COLL/ HA composites) in contact with the outer portion of the brain tissue and loaded with a releasable neuroprotective drug/protein able to diffuse into the brain tissue (as our Tat-Hsp70). Such a system reduces the invasiveness of the surgical procedures and might be potentially refillable from the outside, without repeated deep brain injections.

The major findings from this work are listed as follows: (1) COLL-LMW HA composites did not prevent the diffusion of Tat-Hsp70 in a biologically active form; (2) TatHsp70 released from COLL-LMW HA composites protected cell lines and dopaminergic neurons in 6-OHDAinduced models of PD; (3) the hydrogel-based systems enhanced the effect of Tat-Hsp70 because the same amount of free protein did not convey neuroprotection in vivo; and (4) Tat-Hsp70-loaded composites allowed for improvements of motor functions in a mouse model of PD.

The results from in vivo release (Fig. 7b) suggested that the difference between free Tat-Hsp70 and Tat-Hsp70loaded composites in preservation of TH-positive neurons depends on faster diffusion of the free protein from the target site to the surrounding tissue, thus causing dilution of its small dose. To this end, it is worth underscoring that the effective systemic treatment described by Nagel et al. ${ }^{14}$ required an intraperitoneal injection of $350 \mu \mathrm{g}$ of free recombinant Tat-Hsp70 to be repeated once a day for 8 days. In contrast, the fact that our limited amount of protein $(3.5 \mu \mathrm{g}$, after two injections) was effective when loaded in the composites (Fig. 8) highlights the importance of its prolonged release targeting brain regions directly involved in the neurodegeneration.

We produced good amounts of human recombinant Hsp70 (37 mg/L fermentation broth) and Tat-Hsp70 $(6.3 \mathrm{mg} / \mathrm{L}$ fermentation broth) in $E$. coli with an optimized procedure. Both purified proteins were folded and active, as confirmed by far-UV circular dichroism spectra, ATPase activity assay, and neuroprotection tests with SHSY5Y cells exposed to 6-OHDA, a dopaminergic-selective toxin that triggers oxidative and mitochondrial damage. It is likely to be that neuroprotection was greater for the chimeric than the wild-type protein due to the Tat sequence. For this reason and with a view toward also targeting neurons at an intracellular level, we selected Tat-Hsp70 as a therapeutic agent and confirmed its neuroprotective effect in SH-SY5Y cells exposed to $\mathrm{H}_{2} \mathrm{O}_{2}$ and mesencephalic neurons exposed to $\alpha$-syn, a more specific trigger of neuronal degeneration in PD. Hydrogen peroxide is an inducer of oxidative damage, which is involved in neurodegenerative processes ${ }^{14}$. Its use is not specific for PD, but an increase of oxidative stress is a feature of PD. In addition, the toxic mechanism elicited by the dopaminergic-selective toxin 6-OHDA implies oxidative stress and free radical generation. Therefore, several studies (e.g., ref. ${ }^{32}$.) have exploited $\mathrm{H}_{2} \mathrm{O}_{2}$ in the context of PD-related neurodegeneration.

For hydrogel preparation, we used ultrapure pharmagrade $\mathrm{HA}$ at two molecular weights $\left(1 \times 10^{5} \mathrm{Da}\right.$ and $1.6 \times$ $\left.10^{6} \mathrm{Da}\right)$. The molecular weight of HA significantly influences the mechanical and rheological properties of hydrogel-based systems ${ }^{18}$. In our work, $G$ ' increased with the molecular weight of HA and influenced the injection/ flow behavior, because we achieved higher values of viscosity, and maximum and plateau loads for COLL- 


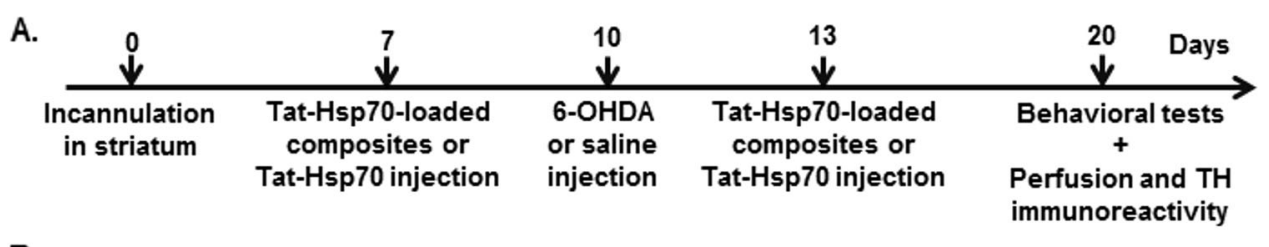

B.
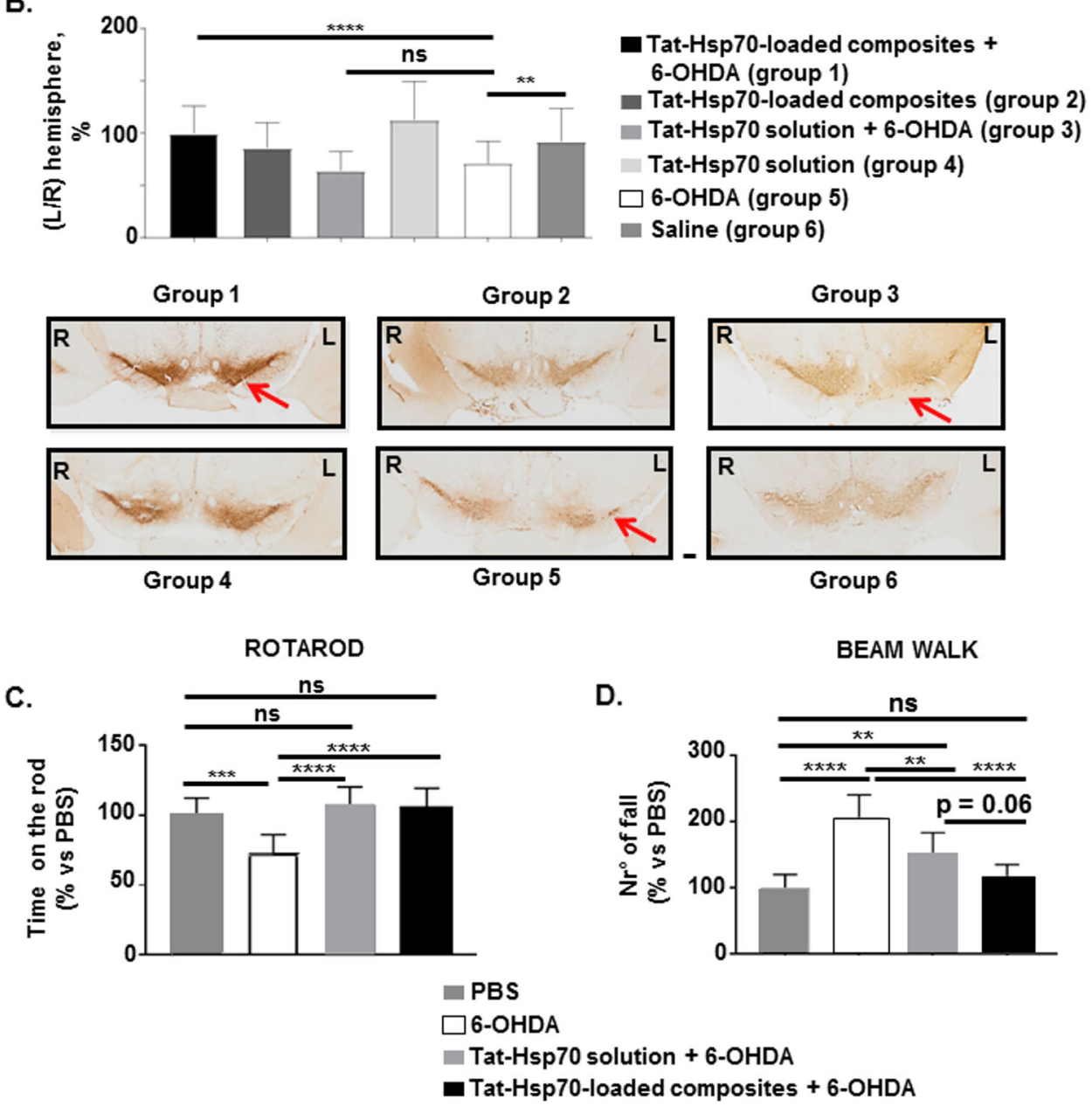

Fig. 8 Hydrogel-mediated Tat-Hsp70 neuroprotection in a mouse model of PD. a Diagram showing the experimental workflow. Numbers with downward arrows above the line indicate the days on which the actions described under the line were performed. b Upper panel: graph bar showing the software-assisted quantification of dopaminergic neurons positive for tyrosine hydroxylase (TH) staining when mice were sacrificed on day 20. $R$ indicates the right brain hemisphere (control) and $L$ indicates the left brain hemisphere (injected). Lower panel: TH signals of each group (10 mice/group). We reported the results as percentages with mean \pm SD. We counted $\sim 200 \mathrm{TH}$-positive neurons in the substantia nigra for each mouse (three to four slices/mouse). Scale bar $=200 \mu \mathrm{m}$. Red arrows indicate the attenuation of TH signal in the substantia nigra due to 6-OHDA triggering neuronal degeneration. We measured sensorimotor deficits using the Rotarod test (c) and beam walk (d). We reported the results as mean \pm SD, 6 replicates/group. We analyzed all the results reported in this figure with one-way ANOVA followed by Tukey's multiple comparisons test. ns, $p$ $>0.05 ;{ }^{* *} p<0.01 ;{ }^{* *} p<0.001 ;{ }^{* * *} p<0.0001$

HMW HA compared with those for COLL and COLLLMW HA gels.

To investigate COLL-HA interactions, we stained hydrogels with Sirius red and Alcian blue. COLL gels showed a regular pattern of fibrils and no blue areas were present, suggesting that Alcian blue does not stain COLL fibrils nonspecifically. COLL-HMW HA semi-IPNs showed a nonhomogeneous structure, with clearly visible blue (HA), red (COLL), and purple (COLL-HA) areas, whereas for COLL-LMW HA gels only blue areas were visible, suggesting that COLL fibrils were homogeneously coated by HA chains, thus preventing Sirius red staining. 
To stress the experimental conditions used to evaluate cytocompatibility, we embedded SH-SY5Y cells in the hydrogels. Although this is a more physiologically relevant method for modeling cell behavior than two-dimensional cultures, cells are more vulnerable in three-dimensional conditions to deleterious stimuli from the surrounding biomaterials, because they are exposed to a reduced availability of oxygen and nutrients, together with the accumulation of catabolites. Performance with time was better for COLL-LMW HA gels or composites. For this reason (together with the superior ultrastructural homogeneity of COLL-LMW HA semi-IPNs), we did not consider COLL-HMW HA composites for the device prototypes.

We also included gelatin particles in our prototypes. The particle concentrations tested $(25,50,100,250$, and $500 \mu \mathrm{g} / \mathrm{mL}$ ) did not affect cell morphology and metabolic activity, suggesting that they can be used safely. Rheological investigation showed that $G^{\prime}$ and viscosity increased after loading 10 and $25 \mu \mathrm{g} / \mathrm{mL}$ particles, but decreased as the particle concentration was further increased. These results confirmed that the concentration selected $(25 \mu \mathrm{g} / \mathrm{mL}$ ) effectively acted as a reinforcement (also in the presence of Tat-Hsp70), thus improving the viscoelastic properties of COLL-LMW HA gels. In addition, the presence of the particles increased the versatility of the prototype by allowing for the loading of Tat-Hsp70 and extension of the delivery period. We explored this possibility and reported the preliminary results related to particle loading and release kinetics in Supplementary Material S4.

We initially assessed in vivo biocompatibility by examining the peripheral inflammatory response after subcutaneous injection. Differently from basic polymer components and unloaded composites, the prototype increased leukocyte recruitment, even though the magnitude of the response was only $\sim 20 \%$ of that of the positive control. As our recombinant Tat-Hsp70 was endotoxin-free, this acute response might depend on the interaction between the Tat epitope and epithelial cells ${ }^{33}$ in the basal epithelial layer of the air pouch. To the best of our knowledge, these effects have not been reported in brain tissue, where many neuroprotective applications of Tat-fused short peptides or full-length proteins have been described $^{34}$. After injecting the Tat-Hsp70-loaded composites, brain inflammation was reduced with time, suggesting that the inflammatory response is transient and primarily due to surgery ${ }^{35}$, whereas the material and its degradation products are well tolerated. We also observed a significant neuroprotective effect of Tat-Hsp70-loaded composites in 6-OHDA-induced models of PD, both at the behavioral and dopaminergic neuronal levels, thus confirming (in accordance with literature) that Tat-Hsp70 is effective in counteracting PD-related degeneration.
It is difficult to compare our release pattern and protein efficacy with those in the literature, because no other studies exist on the localized delivery of chaperones from hydrogels in the striatum. However, as PD is a chronic disorder, a limitation of our system is the short release period. The release period might be extended by TatHsp70 encapsulation in gelatin particles embedded in COLL-LMW HA composites or coupling chemical (crosslinks) to physical interactions in COLL-HA networks. For instance, a previous study showed that $10 \mu \mathrm{L}$ of a self-crosslinking dextran dialdehyde crosslinked gelatin hydrogel had significant behavioral effects in a 6-OHDAinduced rat model of PD by delivering $500 \mu \mathrm{g}$ dopamine over a period of $\sim 2$ weeks ${ }^{36}$.

\section{Conclusions}

Our results support the potential of COLL-LMW HA composites and recombinant Tat-Hsp70 as tools for moving toward effective therapies in PD. The release profile that we optimized is limited in time, but reached the relevant therapeutic goals of neuroprotection of $\mathrm{TH}$ positive dopaminergic neurons and behavioral recovery in our mouse model. Of course, these promising features are limited by the long-lasting clinical course of PD, which makes repeated brain injections unfeasible. However, a possible less invasive evolution of our delivery system might be based on the so-called epi-cortical release approach that was previously described in brain neurodegeneration as an effective strategy using hydrogels ${ }^{30,31}$. Finally, our proposed delivery system also offers a starting point for therapeutic approaches against other CNS neurodegenerative disorders and its clinical translation might gain greatly from the development of less invasive protocols for hydrogel applications.

\section{Acknowledgements}

This work received funding from Fondazione Cariplo (Grant no. 2011-0335). We thank Annalisa Grimaldi (University of Insubria, Varese) for TEM analyses and immunofluorescence on hydrogels; Miriam Ciani, Roberta Ghidoni, and Luisa Benussi (IRCCS Istituto Centro San Giovanni di Dio, Fatebenefratelli, Brescia) for NTA; Luca Barbieri, Roberta Seghezzi, Nino Chirico, Giovanni Antonio Riva (Politecnico di Milano, Milan), Serena Rodilossi, Armando Chierchia, and Daniele Tolomeo (Istituto di Ricerche Farmacologiche Mario Negri IRCCS, Milan) for technical support. A special thank to Felice Volpe and Alessandro Ruggiero (Altergon Italia srl, Morra De Sanctis, Italy) for technical support and suggestions about HA handling and processing. We also thank Judith Baggott (Istituto di Ricerche Farmacologiche Mario Negri IRCCS, Milan) for English editing. The graphical abstract was partially created with BioRender.

\section{Author details}

'Department of Chemistry, Materials and Chemical Engineering "G. Natta", Politecnico di Milano, Milan, Italy. ${ }^{2}$ Department of Neuroscience, Istituto di Ricerche Farmacologiche Mario Negri IRCCS, Milan, Italy. Institute of Polymers, Composites and Biomaterials, National Research Council of Italy, Naples, Italy. ${ }^{4}$ Department of Molecular Biochemistry and Pharmacology, Istituto di Ricerche Farmacologiche Mario Negri IRCCS, Milan, Italy. ${ }^{5}$ Department of Biotechnology and Life Sciences, University of Insubria, Varese, Italy. ${ }^{6}$ Department of Biomedical Sciences, University of Padua, Padua, Italy. ${ }^{7}$ Department of Chemical Science and Materials Technology, National Research Council of Italy, Rome, Italy 


\section{Conflict of interest}

The authors declare that they have no conflict of interest.

\section{Publisher's note}

Springer Nature remains neutral with regard to jurisdictional claims in published maps and institutional affiliations.

Supplementary information is available for this paper at https://doi.org/ 10.1038/s41427-019-0128-8.

Received: 2 August 2018 Revised: 22 January 2019 Accepted: 19 February 2019.

Published online: 14 June 2019

\section{References}

1. Choonara, Y. E., Kumar, P., Modi, G. \& Pillay, V. Improving drug delivery technology for treating neurodegenerative diseases. Expert. Opin. Drug. Deliv. 13, 1029-1043 (2016).

2. Sharma, S. K. \& Priya, S. Expanding role of molecular chaperones in regulating a-synuclein misfolding; implications in Parkinson's disease. Cell. Mol. Life Sci. 74 617-629 (2017)

3. Pankratz, N. \& Foroud, T. Genetics of Parkinson disease. NeuroRx 1, 235-242 (2004).

4. Rizek, P., Kumar, N. \& Jog, M. S. An update on the diagnosis and treatment of Parkinson disease. CMAJ 188, 1157-1165 (2016).

5. Auluck, P. K. Meulener, M. C. \& Bonini, N. M. Mechanisms of suppression of \{alpha\}-synuclein neurotoxicity by geldanamycin in Drosophila. J. Biol. Chem. 280, 2873-2878 (2005).

6. Yang, Q. et al. Regulation of neuronal survival factor MEF2D by chaperonemediated autophagy. Science 323, 124-127 (2009).

7. Fontaine, S. N., Martin, M. D. \& Dickey, C. A. Neurodegeneration and the heat shock protein 70 machinery: implications for therapeutic development. Curr. Top. Med. Chem. 16, 2741-2752 (2016).

8. Lazarev, V. F. et al. Sensitizing tumor cells to conventional drugs: HSP70 chaperone inhibitors, their selection and application in cancer models. Cell Death Dis. 9, 41 (2018).

9. McFarland, N. R. et al. Chronic treatment with novel small molecule Hsp90 inhibitors rescues striatal dopamine levels but not a-synuclein-induced neuronal cell loss. PLoS ONE 9, e86048 (2014).

10. Yurinskaya, M. M. et al. Encapsulated Hsp70 decreases endotoxin-induced production of ROS and TNFa in human phagocytes. Cell Stress Chaperon. 22 163-171 (2017).

11. Shevtsov, M. A. et al. Neurotherapeutic activity of the recombinant heat shock protein $\mathrm{Hsp70}$ in a model of focal cerebral ischemia in rats. Drug Des. Devel. Ther. 8, 639-650 (2014).

12. Abkin, S. V., Pankratova, K. M., Komarova, E. Y., Guzhova, I. V. \& Margulis, B. A. Hsp70 chaperone-based gel composition as a novel immunotherapeutic antitumor tool. Cell Stress Chaperon. 18, 391-396 (2013).

13. Lee, J., Tan, C. Y., Lee, S. K., Kim, Y. H. \& Lee, K. Y. Controlled delivery of heat shock protein using an injectable microsphere/hydrogel combination system for the treatment of myocardial infarction. J. Control Release 137, 196-202 (2009).

14. Nagel, F. et al. Tat-Hsp70 protects dopaminergic neurons in midbrain cultures and in the substantia nigra in models of Parkinson's disease. J. Neurochem. 105, 853-864 (2008).

15. Nikolaeva, T. I., Tiktopulo, E. I., Polozov, R. V. \& Rochev, Y. A. Thermodynamic characteristics of collagen fibrils reconstructed in vitro at different temperatures and concentrations. Biophysics 52, 191-195 (2007).

16. Khaing, Z. Z. et al. High molecular weight hyaluronic acid limits astrocyte activation and scar formation after spinal cord injury. J. Neural Eng. 8, 046033 (2011).
17. Sherman, L. S., Matsumoto, S., Su, W., Srivastava, T. \& Back, S. A. Hyaluronan synthesis, catabolism, and signaling in neurodegenerative diseases. Int. J. Cell Biol. 2015, 368584 (2015).

18. Xin, X., Borzacchiello, A., Netti, P. A., Ambrosio, L. \& Nicolais, L. Hyaluronic-acidbased semi-interpenetrating materials. J. Biomater. Sci. Polym. Ed. 15, 1223-1236 (2004).

19. Oliveira, J. M. et al. Hydrogel-based scaffolds to support intrathecal stem cell transplantation as a gateway to the spinal cord: clinical needs, biomaterials, and imaging technologies. NPJ Regen. Med. 3, 8 (2018).

20. Tsaryk, R. et al. Collagen-low molecular weight hyaluronic acid semiinterpenetrating network loaded with gelatin microspheres for cell and growth factor delivery for nucleus pulposus regeneration. Acta Biomater. 20, 10-21 (2015)

21. Coester, C. J., Langer, K., van Briesen, H. \& Kreuter, J. Gelatin nanoparticles by two step desolvation-a new preparation method, surface modifications and cell uptake. J. Microencapsul. 17, 187-193 (2000).

22. Kilkenny, C., Browne, W. J., Cuthill, I. C., Emerson, M. \& Altman, D. G. Improving bioscience research reporting: the ARRIVE guidelines for reporting animal research. PLoS Biol. 8, e1000412 (2010).

23. Matambo, T. S., Odunuga, O. O., Boshoff, A. \& Blatch, G. L. Overproduction, purification, and characterization of the Plasmodium falciparum heat shock protein 70. Protein Expr. Purif. 33, 214-222 (2004).

24. Nagel, F., Dohm, C. P., Bähr, M., Wouters, F. S. \& Dietz, G. P. Quantitative evaluation of chaperone activity and neuroprotection by different preparations of a cell-penetrating Hsp70. J. Neurosci. Methods 171, 226-232 (2008).

25. Luong, T. N., Carlisle, H. J., Southwell, A. \& Patterson, P. H. Assessment of motor balance and coordination in mice using the balance beam. J. Vis. Exp. 49, 2376 (2011).

26. Klucken, J., Shin, Y., Masliah, E., Hyman, B. T. \& McLean, P. J. Hsp70 reduces alpha-synuclein aggregation and toxicity. J. Biol. Chem. 279, 25497-25502 (2004).

27. Auluck, P. K., Chan, H. Y., Trojanowski, J. Q., Lee, V. M. \& Bonini, N. M. Chaperone suppression of alpha-synuclein toxicity in a Drosophila model for Parkinson's disease. Science 295, 865-868 (2002).

28. Dinca, A., Chien, W. \& Chin, M. T. Intracellular delivery of proteins with cellpenetrating peptides for therapeutic uses in human disease. Int. J. Mol. Sci. 17, 263-275 (2016)

29. Li, J. \& Mooney, D. J. Designing hydrogels for controlled drug delivery. Nat. Rev. Mater. 1, 16071 (2016).

30. Cooke, M. J., Wang, Y., Morshead, C. M. \& Shoichet, M. S. Controlled epi-cortical delivery of epidermal growth factor for the stimulation of endogenous neural stem cell proliferation in stroke-injured brain. Biomaterials 32, 5688-5697 (2011).

31. Tuladhar, A., Morshead, C. M. \& Shoichet, M. S. Circumventing the blood-brain barrier: local delivery of cyclosporin A stimulates stem cells in stroke-injured rat brain. J. Control Release 215, 1-11 (2015).

32. Aleyasin, H. et al. DJ-1 protects the nigrostriatal axis from the neurotoxin MPTP by modulation of the AKT pathway. Proc. Natl Acad. Sci. USA 107, 3186-3191 (2010).

33. Kim, H., Moodley, S. \& Liu, M. TAT cell-penetrating peptide modulates inflammatory response and apoptosis in human lung epithelial cells. Drug Deliv. Transl. Res. 5, 275-278 (2015).

34. Li, X. et al. A novel cell-penetrating peptide protects against neuron apoptosis after cerebral ischemia by inhibiting the nuclear translocation of annexin A1. Cell Death Differ. 26, 260-275 (2019).

35. Kozai, T. D., Jaquins-Gerstl, A. S., Vazquez, A. L., Michael, A. C. \& Cui, X. T. Brain tissue responses to neural implants impact signal sensitivity and intervention strategies. ACS Chem. Neurosci. 6, 48-67 (2015).

36. Senthilkumar, K. S. et al. Unilateral implantation of dopamine-loaded biodegradable hydrogel in the striatum attenuates motor abnormalities in the 6hydroxydopamine model of hemi-parkinsonism. Behav. Brain. Res. 184, 11-18 (2007). 